\title{
Photoelectrochemical Investigation on the Cadmium Sulfide (CdS) Thin Films Prepared Using Spin Coating Technique
}

Ganesh K. Rahane, ${ }^{1, *}$ Sagar B. Jathar, ${ }^{1, *}$ Sachin R. Rondiya, ${ }^{2}$ Yogesh A. Jadhav, ${ }^{1}$ Sunil V. Barma, ${ }^{1}$ Avinash V. Rokade, ${ }^{1}$ Russell W. Cross, ${ }^{2}$ Mamta P. Nasane, ${ }^{1}$ Vijaya S. Jadkar, ${ }^{1}$ Nelson Y. Dzade ${ }^{2}$ and Sandesh R. Jadkar ${ }^{3, *}$

\begin{abstract}
Photoelectrochemical cell technology is one of the simplest technologies, which converts light energy directly into electricity. The synthesis of cadmium sulfide (CdS) nanocrystals (NCs) was performed by the facile hot injection method. The NCs were characterized by different techniques such as XRD, Raman, UV-Vis, FESEM, and XPS. The XRD and Raman patterns confirm the phase pure hexagonal CdS NCs. The band gap of NCs calculated from the UV-Visible spectrum is at 2.64 eV, indicating good absorption in the visible spectrum. XPS analysis confirmed the presence of individual elements in CdS NCs. The CdS thin-films having different thicknesses were prepared on FTO substrates using the spin coating technique. Photoelectrochemical (PEC) investigation of CdS NCs thin-films photoelectrodes was performed by varying its thickness. The increase in the thickness of thin-films increased photocurrent density.
\end{abstract}

Keywords: CdS; Hot-injection Method; Thin films; Photoelectrochemistry; Solar cells.

Received: 25 November 2020; Accepted date: 23 December 2020.

Article type: Research article.

\section{Introduction}

The heavy dependence on fossil fuels to quench the world's energy thirst is not sustainable. The search for low-cost, safe, non-toxic, and sustainable options for green energy is heavily researched. The photoelectrochemical (PEC) technologies are one such class of green technologies that convert light energy into electricity, becoming a promising energy option. The stability of the photoelectrode is a major concern in making PEC devices commercially viable. The widespread adaption of PEC devices strongly depends on the improvement in the photocurrent generated by the photoelectrode under solar illumination. Researchers have adopted different strategies to improve the photocurrent that mainly involves maximizing the semiconductor's light absorption capability and reducing the electrical losses. The anionic, cationic, and co-doping of heteroatoms have been used to tune the bandgap of the

\footnotetext{
${ }^{I}$ School of Energy Studies, Savitribai Phule Pune University, Pune 411007, India

${ }^{2}$ School of Chemistry, Cardiff University, Main Building, Park

Place, Cardiff, CF10 3AT, Wales, UK

${ }^{3}$ Department of Physics, Savitribai Phule Pune University, Pune

411007, India

*Email: sandesh@physics.unipune.ac.in (S. R. Jadkar)

These authors contributed equally
}

photoelectrode material to maximize the light absorption. ${ }^{[1-6]}$ The tweaking of morphologies and orientations of the photoelectrode material with strongly anisotropic electrical properties has improved the photocurrent. ${ }^{[7-9]}$ Many complicated structures like a helix, inverse opal nanostructures, etc., have been used for photoelectrode to reduce the surface reflection of light by multiple scattering. ${ }^{[10,}$ 11] The designing and preparation of high-performance photoelectrode have attracted significant interest from researchers. ${ }^{[12-16]}$ The structure modification of the thin-film photoelectrodes like $\mathrm{TiO}_{2},{ }^{[17-19]} \mathrm{ZnO}_{,}{ }^{[20-22]} \mathrm{WO}_{3},{ }^{[23-25]} \mathrm{BiVO}_{4},{ }^{[26}$, ${ }^{27]}$ etc. with $\mathrm{CdS}$ nanoparticles or quantum dots as modifiers for PEC enhancement have been widely researched. The different strategies have been explored for improvement in the PEC properties of individual CdS thin-films. The preparation of polycrystalline $\mathrm{CdS}$ thin-films with hexagonal crystal structure has been performed, and the weak PEC performance was observed. ${ }^{[28]}$ The aligned $\mathrm{CdS}$ nanowires on a $\mathrm{Cd}$ foil, with anisotropic transport properties, have reported that nanowires have low internal resistance and hence reached good effective charge transfer, thus improving PEC performance. ${ }^{[29]}$ The thinfilm photoelectrode made of self-supported O-doped $\mathrm{CdS}$ nanorod-based hierarchical architecture has dramatically enhanced the PEC response. ${ }^{[30]}$ The photoelectrode thickness also influences the generated photocurrent in PEC devices, and thickness optimization to get the highest photocurrent has proven crucial. ${ }^{[31-33]}$ 
The compound semiconductors have become widespread in photoelectrochemical technologies. The CdS is a group IIVI chalcogenide wide band gap compound semiconductor that behaves like n-type material. CdS are one of the most rigorously studied binary compound semiconductors for photocatalysis, photonics, photovoltaics, and opto-electronics applications. ${ }^{[34-37]} \mathrm{CdS}$ nanocrystals $(\mathrm{NCs})$ have been rigorously studied for photocatalysis by assembling into heterostructures with other 2D materials. ${ }^{[38-43]}$ Various methods have been used to synthesize the CdS NCs, but these methods are costly, unsafe, moisture-sensitive, etc. The sol-gel method, ${ }^{[44]}$ hydrothermal method, ${ }^{[45]}$ solvothermal method, ${ }^{[46]}$ coprecipitation, ${ }^{[47]}$ photochemical method, polyol synthesis, ${ }^{[48}$ ion implantation, ${ }^{[49]}$ microwave-assisted synthesis, ${ }^{[50]}$ and electron-beam evaporation ${ }^{[51]}$ have been used for the synthesis of CdS NCs. The synthesis of device-quality CdS NCs is crucial for various applications. The hot injection technique is an appropriate option because it is low-cost, environmentfriendly, and suitable for large-scale synthesis. Nanocrystal's quality and properties can be modified by changing reaction time, process temperature, and injection temperature.

To the best of our knowledge, the thickness optimization of CdS photoelectrode to enhance the PEC performance has not been studied in detail. The dependence of PEC characteristics on the thickness of CdS thin-films photoelectrode has been explored in the current study. We have synthesized CdS NCs by the facile hot injection method. The as-synthesized NCs were characterized by XRD, UVVisible, Raman, XPS, FESEM, EDS, and photoelectrochemical (PEC) techniques. The CdS NCs thin film with different thicknesses on FTO substrates were prepared by spin coating technique. The CdS photoelectrode of different thicknesses were used for PEC measurements, such as linear sweep voltammetry (LSV) and chronoamperometry (CA). Modifying the thickness of CdS thin-film lead to the change in photocurrent density.

\section{Experiment section 2.1 Chemicals}

Cadmium Sulphate $\left(\mathrm{CdSO}_{4} \cdot 2 \mathrm{H}_{2} \mathrm{O}\right)$, Sulphur powder, Oleylamine (OAm), toluene, Isopropyl alcohol (IPA) was purchased from Sigma Aldrich and were used as received without further purification.

\subsection{Synthesis of CdS NCs}

In a typical synthesis of CdS NCs, $2 \mathrm{mmol}_{\text {of }} \mathrm{CdSO}_{4}$ dissolved in $15 \mathrm{ml} \mathrm{OAm}$ in $100 \mathrm{ml}$ three-neck flask under vacuum with continuous stirring at $130{ }^{\circ} \mathrm{C}$. The solution is degassed for 30 min, followed by an increase in temperature to $250^{\circ} \mathrm{C}$ under argon gas and maintained at $250{ }^{\circ} \mathrm{C}$ before sulphur-OAm injection. The appearance of a clear solution indicates the formation of the Cd-oleate complex. The sulphur-OAm is prepared by sonication of $2 \mathrm{mmol}$ of sulphur powder in $5 \mathrm{ml}$ of OAm for $15 \mathrm{~min} .5 \mathrm{~mL}$ of sulphur-OAm is quickly injected in Cd-oleate solution, immediately turns the color of solution pale yellow attributed to the nucleation. The reaction is allowed to continue for the next $15 \mathrm{~min}$ for particle growth, followed by naturally cooling to room temperature. The solution of $40 \mathrm{ml}$ IPA and $5 \mathrm{ml}$ toluene is added to collect the residue and remove the unreacted precursor by centrifugation at $5000 \mathrm{rpm}$. The washing is repeated 3 times. Finally, the $\mathrm{CdS}$ NCs powder sample is collected by drying the precipitate under an IR lamp and used for further characterization.

\subsection{CdS Thin Film Preparation}

The obtained CdS NCs were dispersed in $100 \mathrm{mg} / \mathrm{ml}$ of the toluene solution, and the mixture was sonicated for $3 \mathrm{hrs}$ to form a thick solution. The $1 \mathrm{~cm} \times 1 \mathrm{~cm}$ fluorine-doped tin oxide (FTO) substrates were cleaned with the soap solution, distilled water, ethanol, acetone, and followed by drying with $\mathrm{N}_{2}$ gas. The prepared CdS ink was deposited on FTO by using the spin coat technique at $1200 \mathrm{rpm}$ for $12 \mathrm{~s}$. Similarly, the different layers of CdS NCs (2, 6, and 10) were deposited on the FTO substrate. The photoelectrochemical response of CdS thin film photoelectrode with different layers $(2,6$, and 10$)$ are systematically studied.

\subsection{Material Characterization}

The different characterization techniques were used to investigate as-synthesized $\mathrm{CdS}$ NCs systematically. The structural properties were studied with $\mathrm{x}$-ray diffraction (XRD) performed with an X-ray diffractometer (Bruker D8 Advance, Germany) with $\mathrm{Cu}-\mathrm{K} \alpha$ radiation $(\lambda=1.54 \AA)$. The phase purity information is derived from Raman analysis using Raman spectroscopy (Horibra-Jobin Yvon LABRAM-HR) with an excitation source of $532.8 \mathrm{~nm}$ line of the laser. The optical properties of nanocrystals were studied with JASCO, V-670 UV-visible spectrophotometer. The field emission scanning electron microscopy (FESEM) images were obtained from Quanta FEG 450 attached with Energy Dispersive X-ray (EDX). The photoelectrochemical measurements were carried out using an electrochemical workstation Metrohm Potentiostat/Galvanostat (Autolab PGSTAT302N).

\section{Results discussion}

\subsection{Structural and composition properties}

The powder XRD pattern of as-synthesized CdS NCs is shown in Fig.1(a). The sharp and intense peaks refer to different crystalline planes with different orientations of crystals. The XRD pattern of NCs exhibit diffraction peaks at $25.71^{\circ}$, $27.31^{\circ}, 29.02^{\circ}, 37.35^{\circ}, 44.55^{\circ}, 48.66^{\circ}$, and $52.67^{\circ}$, which corresponds to (100), (002), (101), (102), (110), (103), and (112) crystal planes, respectively. The XRD pattern of NCs is in good agreement with JCPDS data (JCPDS No: 01-080-0006) of pure hexagonal CdS NCs. The average crystallite size of NCs is calculated using the Scherrer formula, $D=0.9 \lambda / \beta \cos \theta$, where $\lambda$ is the wavelength of $\mathrm{x}$-rays $(1.54 \AA), \theta$ is the Bragg angle, and $\beta$ is the full width at half maximum (FWHM) in radians. The average crystallite size calculated after XRD pattern analysis is $\mathrm{D}=7.13 \mathrm{~nm}$. The length of dislocation lines 
per unit volume of the crystal, i. e. mean dislocation density, is calculated as $2.41 \times 10^{-2}$ from Williamson-Smallman relation, $\delta=1 / \mathrm{D}^{2}$. The broadening $\left(\beta_{\mathrm{hkl}}\right)$ of diffraction peak corresponding to typical (hkl) plane consists of broadening due to crystal strain $\left(\beta_{\mathrm{S}}\right)$ and crystallite size $\left(\beta_{\mathrm{D}}\right)$. The broadening $\left(\beta_{\mathrm{hkl}}\right)$ is given by the equation,

On reorganizing,

$$
\beta_{\mathrm{hkl}}=4 \varepsilon \tan \theta+\frac{\mathrm{K} \lambda}{\mathrm{D} \cos \theta}
$$

$$
\frac{\beta_{\mathrm{hkl}} \cos \theta}{\lambda}=\frac{K}{D}+\frac{4 \varepsilon \sin \theta}{\lambda}
$$

The crystal lattice strain is calculated from the WilliamsonHall $(\mathrm{W}-\mathrm{H})$ analysis in which we plotted $\beta_{\mathrm{hkl}} \cos \theta$ against $(4 \sin \theta) / \lambda$ and the intercept value of the fitted line gives the crystal strain. The crystal strain value obtained from $\mathrm{W}-\mathrm{H}$ analysis is $7.65 \times 10^{-2}$. The Raman spectrum of the synthesized nanocrystals is shown in Fig. 1(b). The spectrum shows two major peaks at $300 \mathrm{~cm}^{-1}$ and $600 \mathrm{~cm}^{-1}$, which refers to longitudinal optical (LO) phonon vibrational frequencies and agree with the earlier report. ${ }^{[52]}$
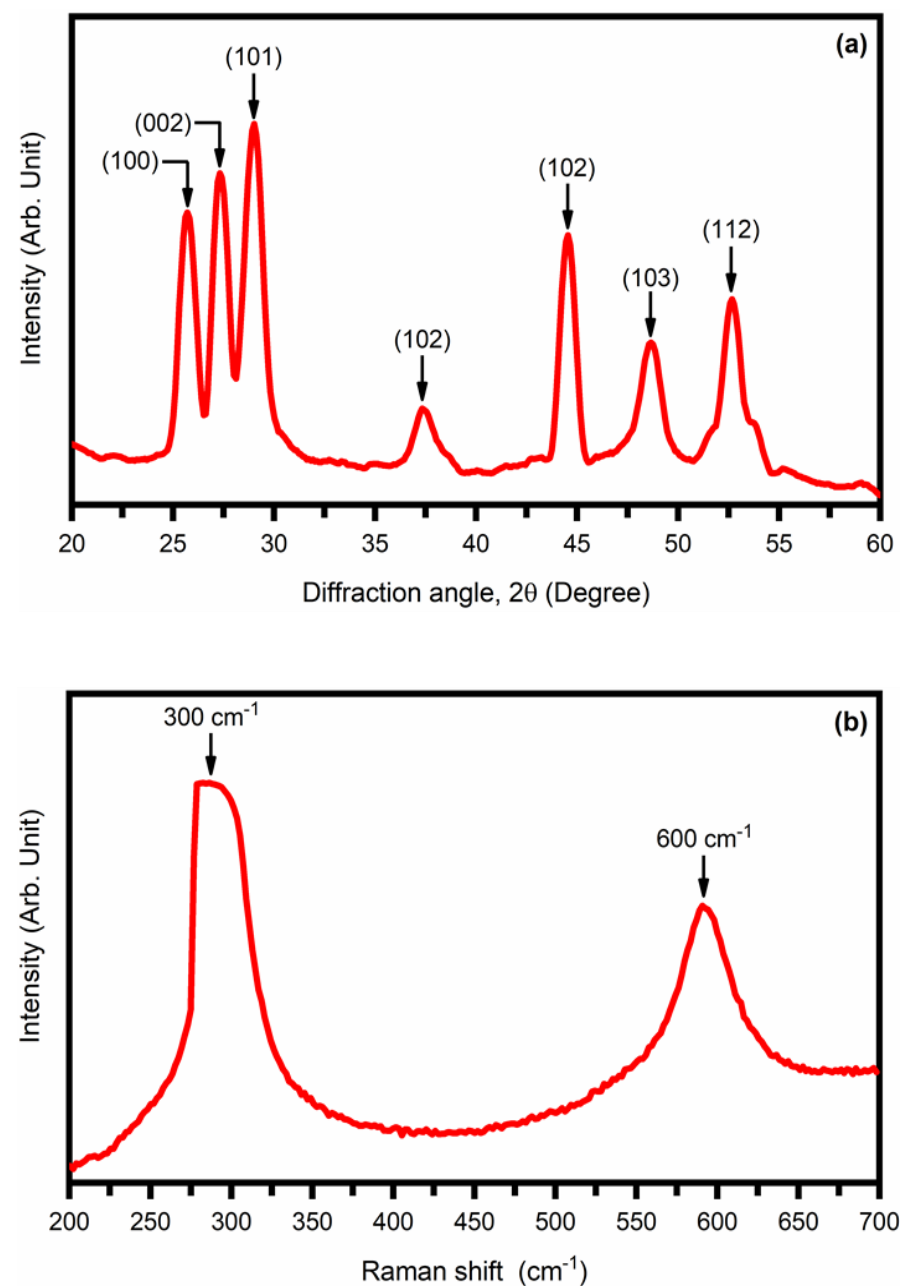

Fig. 1 (a) XRD pattern and (b) Raman spectrum of CdS NCs.

X-ray photoelectron spectroscopy analysis was used to investigate the oxidation states of the surface elements of obtained nanocrystals. Fig. 2(a) shows the XPS survey spectrum and includes peaks from Cd, S, C, and O. Fig. 2(b) shows the XPS spectrum of Cd $3 d$ with peaks at 406.30 and $413.10 \mathrm{eV}$ corresponding to $\mathrm{Cd} 3 \mathrm{~d}_{3 / 2}$ and $\mathrm{Cd} 3 \mathrm{~d}_{5 / 2}$, respectively. The XPS spectrum of $\mathrm{S} 2 \mathrm{p}$ shown in Fig. 2(c) exhibits peaks at $162.60,163.80$, and $169.2 \mathrm{eV}$ corresponding to $\mathrm{S} 2 \mathrm{p}_{3 / 2}, \mathrm{~S}$ $2 \mathrm{p}_{1 / 2}$, and surface sulphate species $\left(\mathrm{SO}_{4}\right)$, respectively. The presence of surface impurities and oxidation of the CdS thin film's surface material due to exposure to the air leads to the photo- corrosion of the surface material. It gives the sulphate $\left(\mathrm{SO}_{4}\right)$ peak in the XPS spectra. ${ }^{[53,54]}$ The peaks of O 1s and C $1 \mathrm{~s}$ at 284.8 and $530.80 \mathrm{eV}$ are likely due to contaminant adsorbed species, respectively. ${ }^{[55]}$
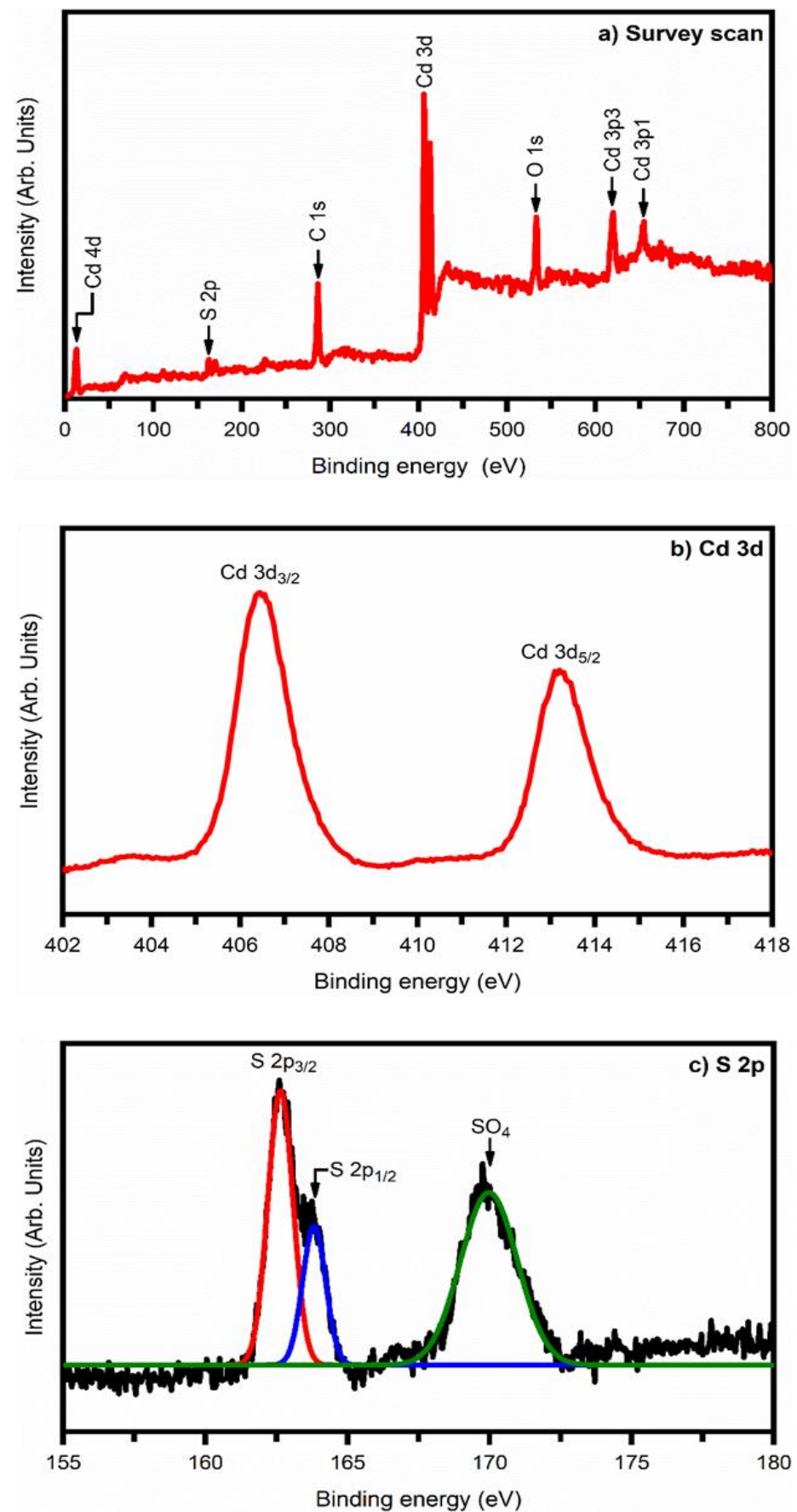

Fig. 2 (a) XPS survey spectra for CdS NCs. (b) and (c) Highresolution XPS spectrum of $\mathrm{Cd} 3 \mathrm{~d}$ and $\mathrm{S} 2 \mathrm{p}$, respectively. 

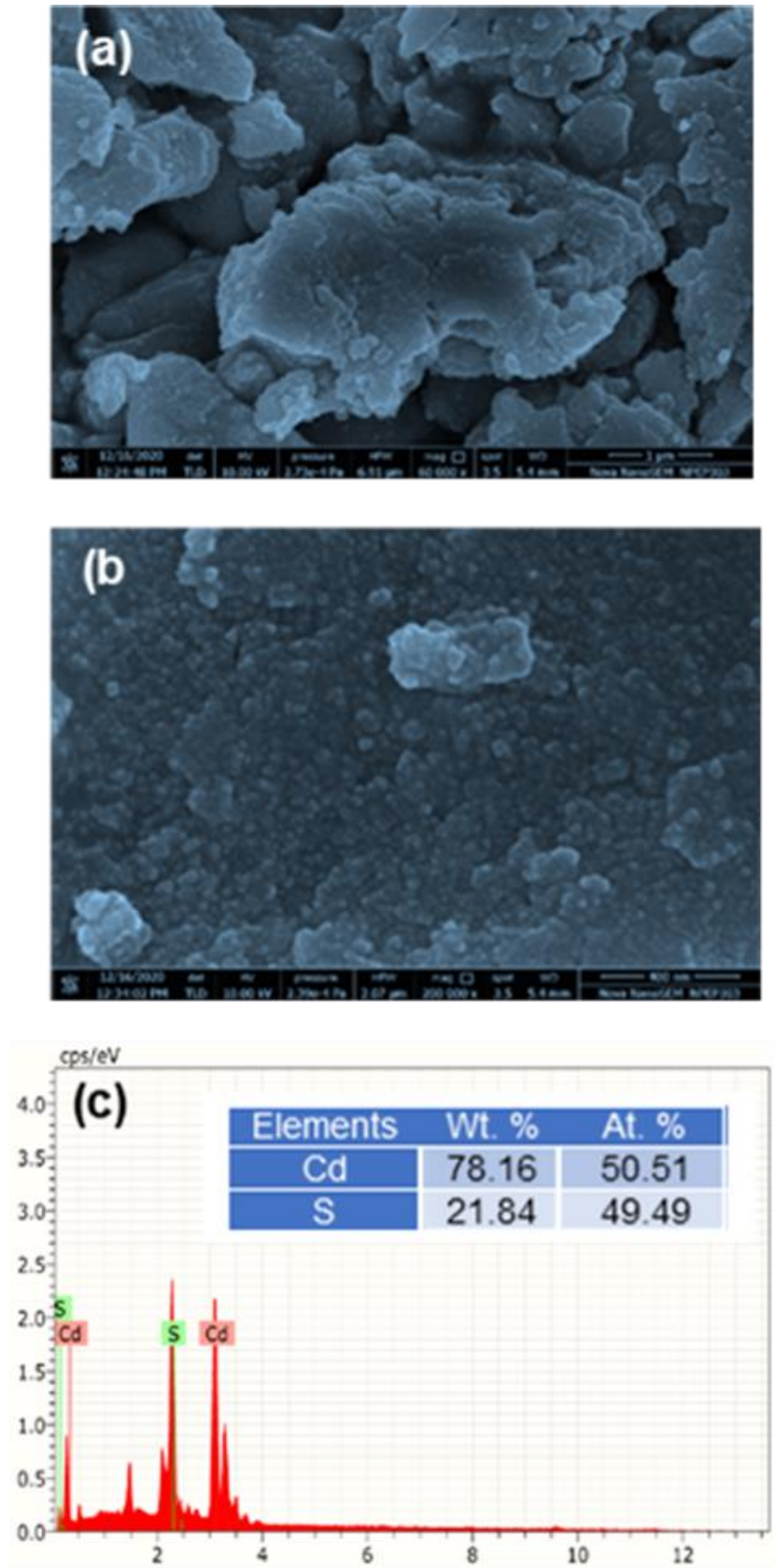
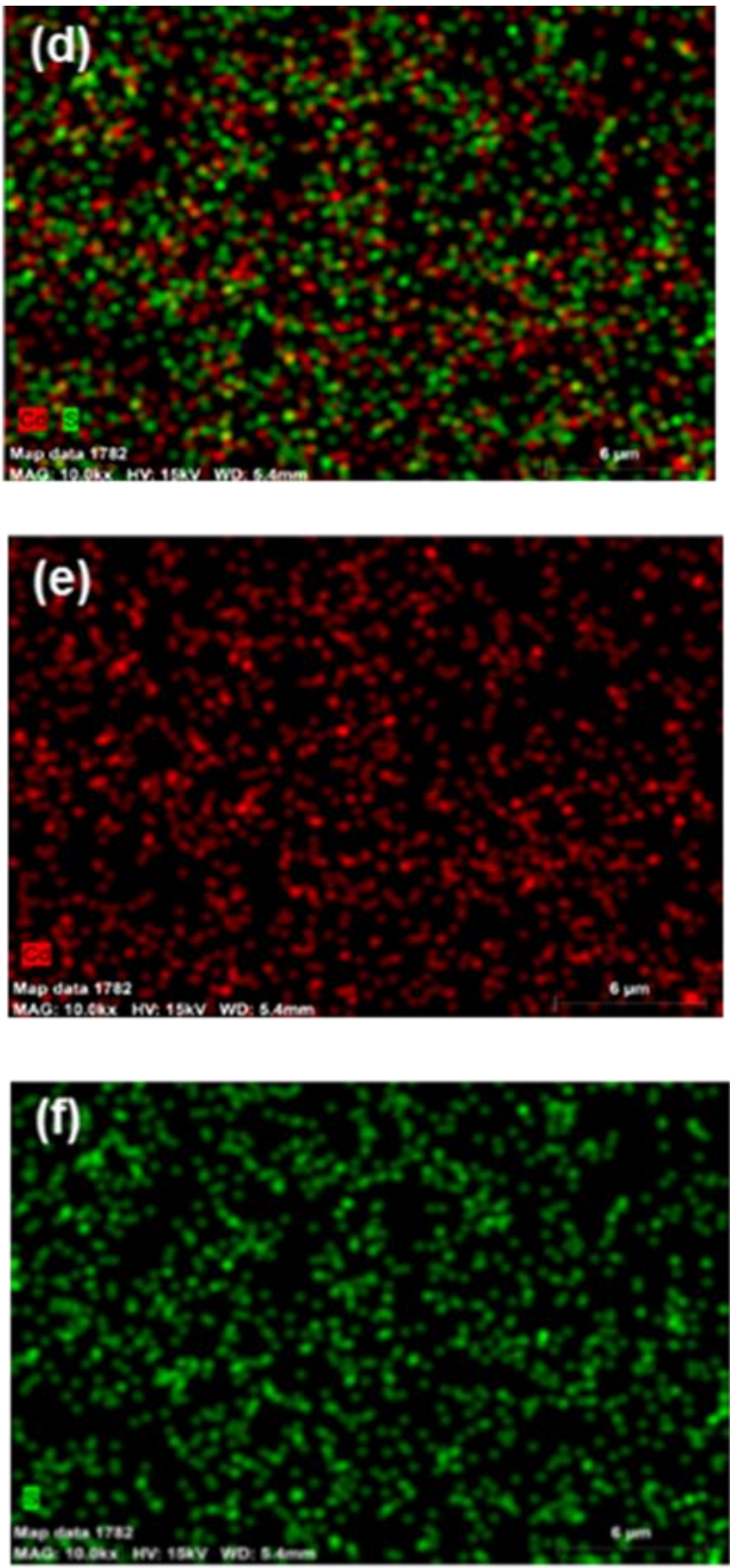

Fig. 3 (a) and (b) FESEM images of CdS NCs at different resolutions (c) EDX spectrum CdS NCs (d) Distribution of Cd and $\mathrm{S}$ in a single FESEM image, (e) and (f) Distribution of elements $\mathrm{Cd}$ and $\mathrm{S}$ present in the material.

The field emission scanning electron microscopy (FESEM) 3.2 Optical properties images of the synthesized CdS NCs for different resolutions are shown in Fig. 3(a) and (b). Fig. 3(a) shows the significant clustering of the CdS NCs. The surface morphology of the CdS NCs is close to a spherical shape. The EDAX spectrum of CdS NCs is shown in Fig. 3(c). The EDAX spectrum reveals $\mathrm{Cd}$ and $\mathrm{S}$ 's presence in the correct atomic percent, i. e., close to $50 \%$ each, which confirms the high-quality nearly stoichiometric characteristics of the CdS NCs. This ensures the elemental composition of CdS NCs. EDS elemental mapping was performed out to get the distribution profile of elements for as-synthesized $\mathrm{CdS} \mathrm{NCs}$ and the results are shown in Fig. 3(d-f)" after "elemental composition of CdS NCs.

The optical properties were investigated with UV-Visible spectroscopy. The absorption spectrum for the cadmium sulfide NCs is shown in Fig. 4(a), indicating strong absorption in the range around $300-500 \mathrm{~nm}$ with an absorption edge at $516 \mathrm{~nm}$. The Tauc's relation is important in the calculation of optical band gap energy of CdS nanocrystals. It shows the dependence of the absorption coefficient $(\alpha)$ on the photon energy $(h v)$ by relation, $(\alpha h v)=B\left(h v-E_{g}\right)^{n}$ where B is Tauc's constant, which is a parameter independent of photon energy, $v$ is photon frequency and $\mathrm{E}_{\mathrm{g}}$ is band gap of the material, $\mathrm{n}$ refers to the type of transition and equal to $1 / 2$ in case $\mathrm{CdS}$ which is direct transition material. The band gap energy is the intercept obtained from the extrapolated line on the energy $(\mathrm{h} v)$ 
axis in the Tauc plot, i.e. $(\alpha \mathrm{h} v)^{1 / 2}$ vs. photon energy (hv) plot. The optical band gap obtained from the Tauc's plot shown in Fig. 4(b) is $2.64 \mathrm{eV}$. The structural, composition, and optical characterizations were performed and deemed appropriate for photoelectrochemical applications.
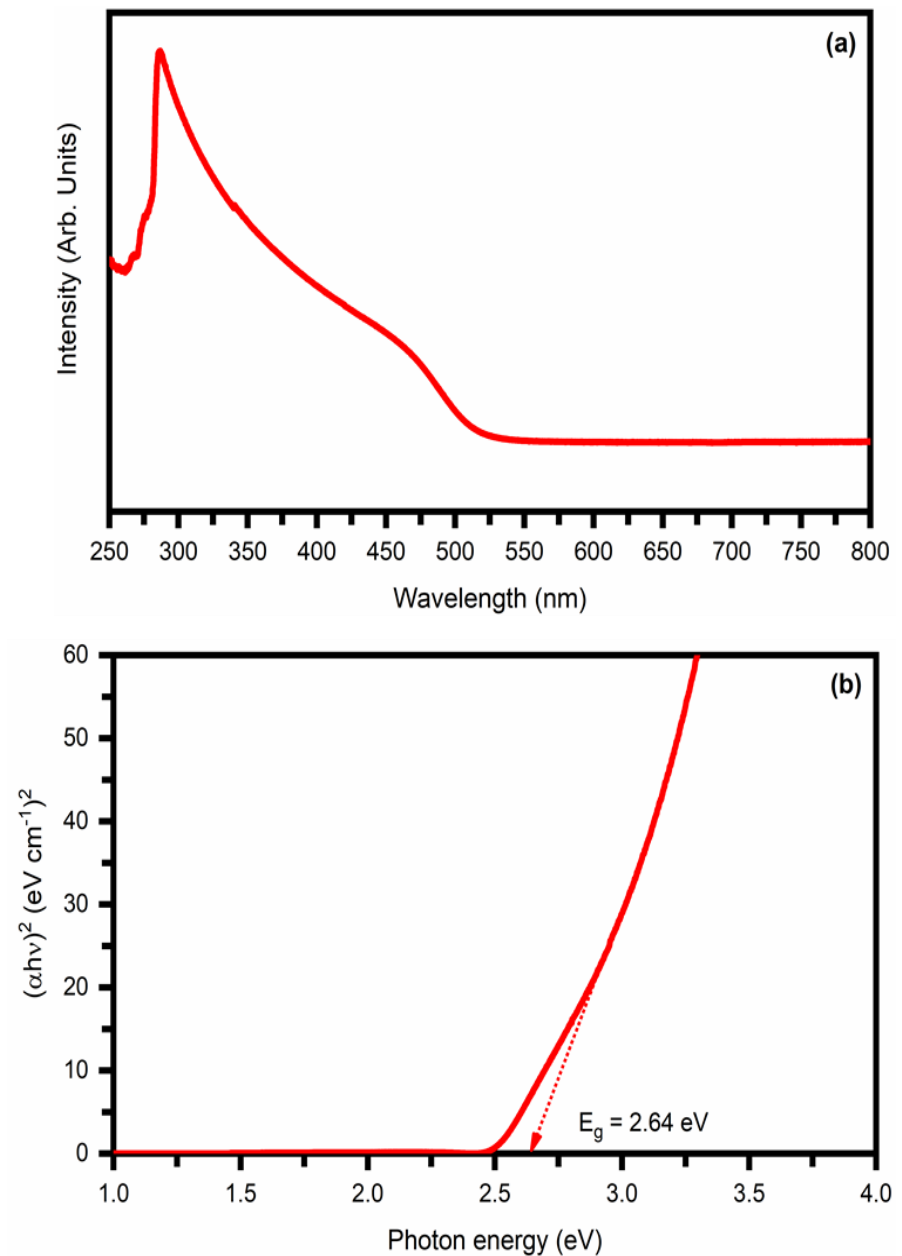

Fig. 4 (a) UV-Vis absorption spectra and (b) Tauc's plot of CdS NCs.

\subsection{Photoelectrochemical Properties}

The photoelectrochemical investigation was performed with the standard three-electrode system comprising of saturated calomel electrode (SCE), platinum plate, and photoelectrode corresponding to reference electrode, a counter electrode, and the working electrode, respectively as shown in Fig. 5. The voltage is measured across the working and reference electrode, whereas the current is measured between the working electrode and the counter electrode. The n-type CdS thin film on the FTO substrate serves as a working photoelectrode. The $0.5 \mathrm{M} \mathrm{Na}_{2} \mathrm{SO}_{4}$ at $\mathrm{pH} 7$ is used as a supporting electrolyte. The physicochemical mechanisms occurring at the semiconductor/electrolyte interface during photoelectrolysis of water principally include efficient light absorption, charge segregation, charge migration, and redox reaction at the surface. The electrons from the $\mathrm{CdS}$ photoelectrode get excited from the valence band to the conduction band, and holes are left behind in the valence band under the photons' illumination with energy greater than the band gap energy of the material. The redox reaction occurs at the CdS and electrolyte interface, thus converting the solar energy to chemical energy. The holes from the valance band of the n-type semiconductor $\mathrm{CdS}$ photoelectrode recombine with water to give oxygen. The hydrogen ion combines with electrons to provide hydrogen at the counter electrode. The reactions taking place at different electrodes are shown in Fig. 5. The linear sweep voltammetry (LSV) and chronoamperometry (CA) measurements were performed for the photoelectrochemical investigation of $\mathrm{CdS}$ thin film photoelectrode of different thicknesses. The CdS photoelectrodes with the number of spin-coated layers as 2, 6 , and 10 of the CdS NCs dispersed in toluene were prepared and used as photoelectrode in PEC cell to study the PEC response. The different spin-coated layers indicate the increase in the thickness of the CdS photoelectrode. The LSV involves a variation of the photoelectrode potential at a constant rate throughout the scan and related current measurement. The scan rate was kept constant at around $100 \mathrm{mV} / \mathrm{s}$ for all measurements. The solar simulator AM $1.5 \mathrm{G}\left(100 \mathrm{~mW} / \mathrm{cm}^{2}\right)$ was used for photoelectrochemical (PEC) measurements.

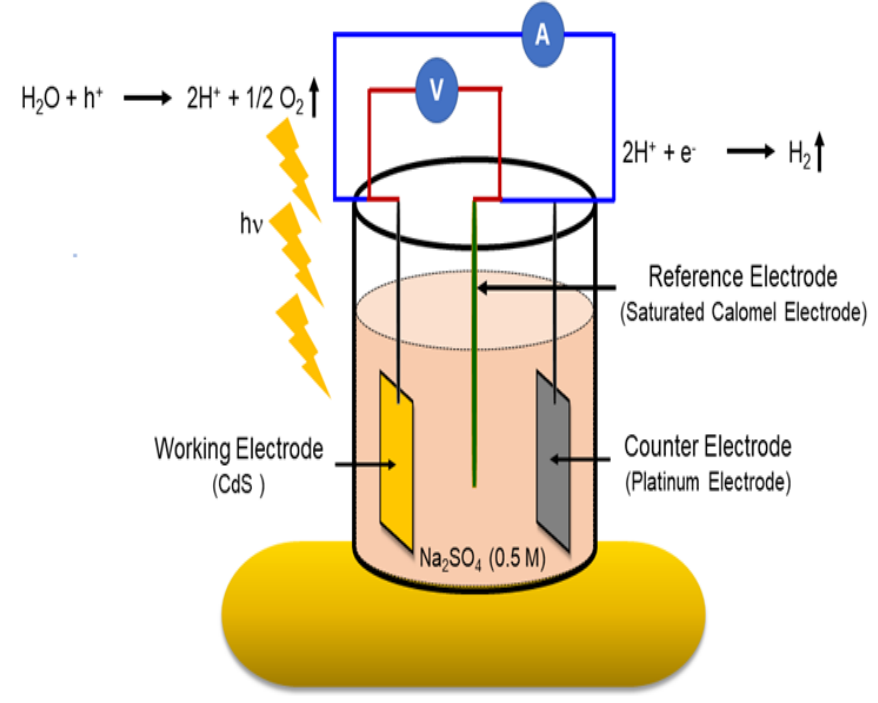

Fig. 5 Photoelectrochemical workstation.

The band gap and the thickness of photoelectrode material are critical factors that influence the number of absorbed photons and thus affect the PEC performance. The full harvesting of the solar spectrum requires the photoelectrode material's thickness to be larger than the incident solar radiation's penetration depth. If the minority-carriers' diffusion length is larger than the photoelectrode material's thickness, then the charge carriers' recombination rate is lower compared to the thicker photoelectrode. If the diffusion length of the minority-carriers is smaller than the photoelectrode material's thickness, the photo-excited charge carrier's recombination rate will be higher even though the number of photons absorbed is larger than the thinner photoelectrode case. The LSV of different CdS samples with varied thicknesses, i. e., various spin-coated layers, were performed, and results are 
shown in Fig. 6(a). The J-V curve for no illumination shows a minimal current, almost zero, because of non-faradic reaction. The J-V curve shows a sharp increase in photocurrent upon illumination as compared to dark. The photocurrent values obtained upon illumination were $12 \mu \mathrm{A}, 18 \mu \mathrm{A}$, and $21 \mu \mathrm{A}$ corresponding to spin coating layers 2,6 , and 10 . Thus, an increase in the CdS photoelectrode thickness resulted in increased photocurrent upon solar illumination. The CA measurement involves measuring current as a function of time when a potential step sufficient to cause an electrochemical reaction is applied to an electrode. The transient photocurrent responses to on-off illumination of spin-coated CdS thin film on FTO substrate is shown in Fig. 6(b). The increase in the number of spin-coated layers, $i . e$. thickness of thin-film thickness, exhibited an increase in photocurrent.
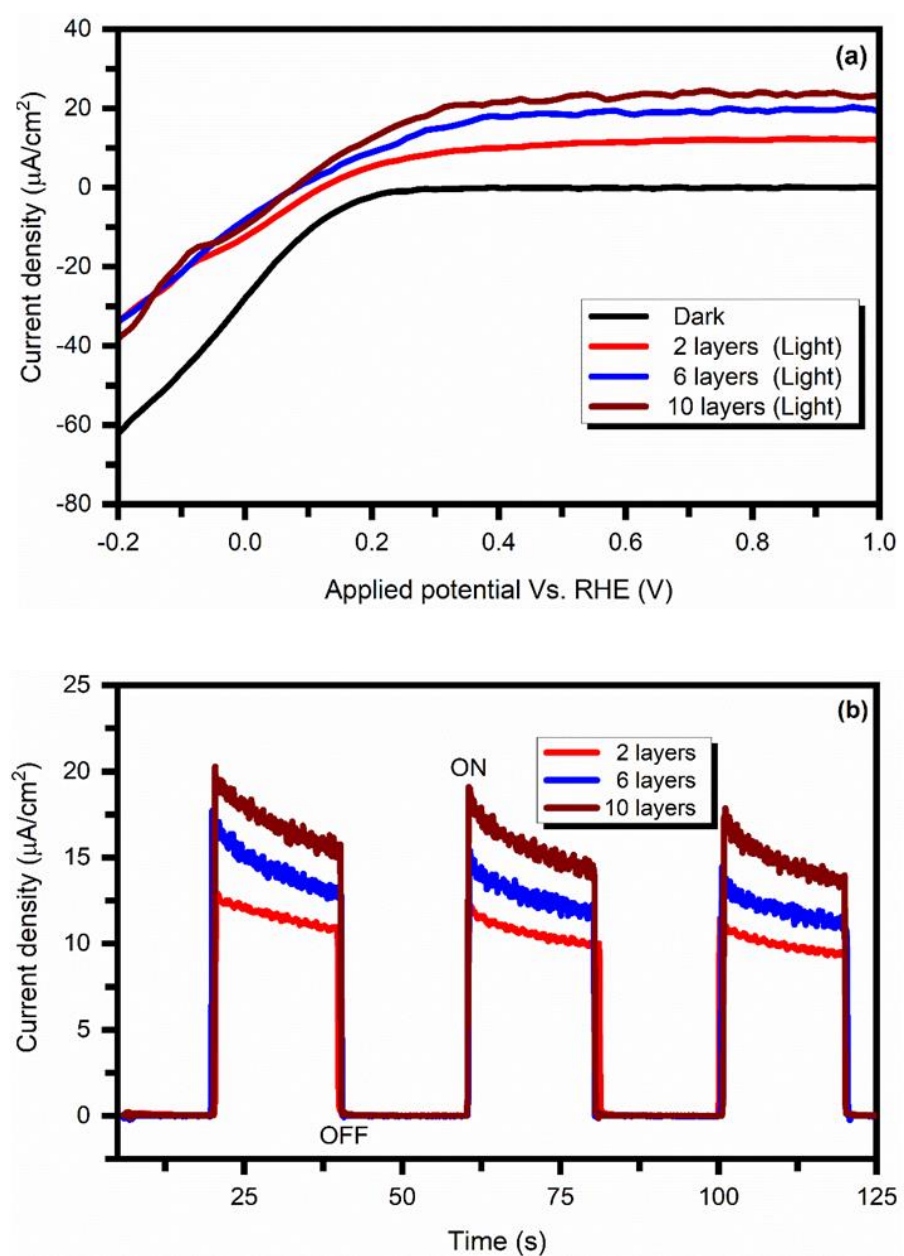

Fig. 6 PEC measurements (a) Linear Sweep voltammetry (LSV) response (b) Chronoamperometry response (light $\mathrm{ON} / \mathrm{OFF}$ ) of CdS photoelectrode formed from the different spin-coated layers.

\section{Conclusions}

The CdS nanocrystals were synthesized by the facile hot injection method and were characterized by different techniques such as XRD, Raman, UV-Vis spectroscopy, FESEM, and XPS. We prepared different working electrodes of CdS with varying thicknesses by the Spin Coating technique. The photoelectrochemical investigation was performed on working electrodes of different thicknesses. The increase in the thickness of CdS thin film leads to an increase in photocurrent density.

\section{Acknowledgement}

Sachin R. Rondiya, Russell W. Cross, and Nelson Y. Dzade acknowledge the UK Engineering and Physical Sciences Research Council (EPSRC) for funding (Grant No. EP/S001395/1). Yogesh A. Jadhav thanks SPPU PDF and School of Energy Studies, SPPU, for financial support and laboratory facilities access. Sandesh R. Jadkar is thankful to the University Grants Commission (UPE program), New Delhi, and Indo-French Centre for the Promotion of Advanced Research-CEFIPRA, Department of Science and Technology, New Delhi for special financial support.

\section{Conflict of interest}

There is no conflict of interest.

\section{Supporting information}

Not Applicable

\section{References}

[1] S. U. M. Khan, M. Al-Shahry and W. B. Ingler, Science, 2002, 297, 5590, 2243-2245, doi: 10.1126/SCIENCE.1075035.

[2] R. Asahi, T. Morikawa, T. Ohwaki, K. Aoki and Y. Taga, Science, 2001, 293, 5528, 269-271, doi: 10.1126/SCIENCE.1061051.

[3] J. H. Park, S. Kim and A. J. Bard, Nano Lett., 2006, 6, 24-28, doi: 10.1021/NL051807Y.

[4] C. Liu, F. Wang, S. Zhu, Y. Xu, Q. Liang and Z. Chen, J. Colloid Interface Sci., 2018, 530, 403-411, doi: 10.1016/J.JCIS.2018.07.003.

[5] I. S. Cho, C. H. Lee, Y. Feng, M. Logar, P. M. Rao, L. Cai, D. R. Kim, R. Sinclair and X. Zheng, Nat. Commun., 2013, 04, 1723, 1-8, doi: 10.1038/NCOMMS2729.

[6] C. Wang, Z. Chen, H. Jin, C. Cao, J. Li and Z. Mi, J. Mater. Chem., 2014, 2, 17820-17827, doi: 10.1039/C4TA04254A.

[7] Y. Zhou, L. Wang, S. Chen, S. Qin, X. Liu, J. Chen, D.-J. Xue, M. Luo, Y. Cao, Y. Cheng, E. H. Sargent and J. Tang, Nat. Photonics, 2015, 9, 409-415, doi: 10.1038/NPHOTON.2015.78.

[8] L. Wang, D.-B. Li, K. Li, C. Chen, H.-X. Deng, L. Gao, Y. Zhao, F. Jiang, L. Li, F. Huang, Y. He, H. Song, G. Niu and J. Tang, Nat. Energy, 2017, 2, 17046, 1-9, doi: 10.1038/NENERGY.2017.46.

[9] W. Yang, J. Ahn, Y. Oh, J. Tan, H. Lee, J. Park, H. C. Kwon, J. Kim, W. Jo, J. Kim and J. H. Moon, Adv. Energy Mater., 2018, 8, 1702888, 1-11, doi: 10.1002/AENM.201702888.

[10] X. Shi, I. Y. Choi, K. Zhang, J. Kwon, D. Y. Kim, J. K. Lee, S. H. Oh, J. K. Kim and J. H. Park, Nat. Commun., 2014, 5, 4775, 1-8, doi: 10.1038/NCOMMS5775.

[11] Y. Oh, W. Yang, J. Tan, H. Lee, J. Park and J. Moon, Adv. Funct. Mater., 2019, 29, 1900194, 1-10, doi: 10.1038/NCOMMS5775. 
[12] A. Eftekhari, V. J. Babu and S. Ramakrishna, Int. J. Hydro. Energy, 2017, 42, 11078-11109, 10.1016/J.IJHYDENE.2017.03.029.

[13] Y. He, T. Hamann and D. Wang, Chem. Soc. Rev., 2019, 48, 2182-2215, doi: 10.1039/C8CS00868J.

[14] X. Sheng, T. Xu and X. Feng, Adv. Mater., 2019, 31, 1805132, 1-29, doi: 10.1002/ADMA.201805132.

[15] N. Zhang, H. Zheng, Y. Guo, J. Feng, Z. Li and Z. Zou, ACS Sustain. Chem. Eng., 2019, 7, 10509-10515, doi: 10.1021/ACSSUSCHEMENG.9B01067.

[16] H. He, A. Liao, W. Guo, W. Luo, Y. Zhou and Z. Zou, Nano Today, 2019, 28, 100763, doi: 10.1016/J.NANTOD.2019.100763. [17] J. Zhong, Q. Wang and X. Xu, J. Electrochem. Soc., 2014, 161, 10, 656-659, doi: 10.1149/2.0691410JES.

[18] S. Han, Y.-C. Pu, L. Zheng, J. Z. Zhang and X. Fang, J. Mater. Chem., 2015, 3, 22627-22635, doi: 10.1039/C5TA07100C.

[19] X. Jiang, M. Sun, Z. Chen, J. Jing and C. Feng, J. Alloys Compd., 2020, 816, 152533, 1-11, doi: 10.1016/J.JALLCOM.2019.152533.

[20] C. Yao, B. Wei, H. Ma, Hui Li, L. Meng, X. Zhang and Q. Gong, Journal of Power Sources, 2013, 237, 295-299, doi: 10.1016/J.JPOWSOUR.2013.02.062.

[21] C. Li, T. Ahmed, M. Ma, T. Edvinsson and J. Zhu, Appl. Catal. B-Environ., 2013, 138, 175-183, doi: 10.1016/J.APCATB.2013.02.042.

[22] Y. Bu, Z. Chen, W. Li and J. Yu, ACS Appl. Mater. Interface, 2013, 5, 5097-5104, doi: 10.1021/AM400964C.

[23] Y. Wang, C. Gao, S. Ge, J. Yu and M. Yan, Biosens. Bioelectron., 2016, 85, 205-211, doi: 10.1016/J.BIOS.2016.05.015.

[24] Y. Liu, Y. Cui, F. Huang and X. Yang, RSC Adv., 2016, 6, 16668-16672, doi: 10.1016/J.JALLCOM.2015.11.030.

[25] J. Jing, Z. Chen, Y. Bu and L. Xu, J. Electrochem. Soc., 2016, 163, 928-926, doi: 10.1149/2.0141702JES.

[26] J. Jiang, M. Wang, R. Li, L. Ma and L. Guo, Int. J. Hydro. Energy, 2013, 38, 13069-13076, doi: 10.1016/J.IJHYDENE.2013.03.057.

[27] L. P. Li, M. Liu and W. D. Zhang, J. Solid State Electrochem., 2018, 22, 2569-2577, doi: 10.1007/S10008-018-3973-4.

[28] D. Boosagulla, S. Mandati, R. Allikayala and B. V. Sarada, ECS J. Solid State Sci. Technol., 2018, 7, 440, 440-446, doi: 10.1149/2.0261808JSS.

[29] W. Kim, D. Monllor-Satoca, W.-S. Chae, M. A. Mahadik and J. S. Jang, Appl. Surf. Sci., 2019, 463, 339-347, doi: 10.1016/J.APSUSC.2018.08.127.

[30] Y. Yu, Y. Huang, Y. Yu, Y. Shi and B. Zhang, Nano Energy, 2018, 43, 236-243, doi: 10.1016/J.NANOEN.2017.11.051.

[31] J. Luo, L. Steier, M.-K. Son, M. Schreier, M. T. Mayer and M. Grätzel, Nano Lett., 2016, 16, 1848-1857, doi: 10.1021/ACS.NANOLETT.5B04929.

[32] P. Dias, M. Schreier, S. D. Tilley, J. Luo, J. Azevedo, L. Andrade, D. Bi, A. Hagfeldt, A. Mendes, M. Grätzel and M. T. Mayer, Adv. Energy Mater., 2015, 5, 1501537, 1-9, doi: 10.1002/AENM.201501537.
[33] S. A. Vanalakar, S. S. Mali, M. P. Suryawanshi, N. L. Tarwal, G. L. Agawane, K. V. Gurav, S. W. Shin, A. V. Moholkar, J. H. Kim and P. S. Patil, Z. Phys. Chem., 2014, 228, 817-827, doi: 10.1515/ZPCH-2014-0510.

[34] B. Tell, T. C. Damen and S. P. S. Porto, Phys. Rev., 1966, 144, 771-774, doi: 10.1103/PHYSREV.144.771.

[35] D. G. Thomas, J. J. Hopfield and M. Power, Phys. Rev., 1960, 119, 570-574, doi: 10.1103/PHYSREV.119.570.

[36] K. W. Boer, Energy Convers. Manag., 2011, 52, 426-430, doi: 10.1016/J.ENCONMAN.2010.07.017.

[37] N. Qutub and S. Sabir, J. Nanosci. Nanotechnol., 2012, 8, 111-120, url: http://www.ijnnonline.net/article_3916.

[38] C. Han, Z. Chen, N. Zhang, J. C. Colmenares and Y. J. Xu, Adv. Funct. Mater, 2015, 25, 221-229, doi: 10.1002/ADFM.201402443.

[39] R. Bera, S. Kundu and A. Patra, ACS Appl. Mater. Interfaces, 2015, 7, 13251-13259, doi: 10.1021/ACSAMI.5B03800.

[40] N. Zhang, Y. Zhang, X. Pan, X. Fu, S. Liu and Y.-J. Xu, J. Phys. Chem. C, 2011, 115, 23501-23511, doi: $10.1021 / \mathrm{JP} 208661 \mathrm{~N}$.

[41] F. Ma, Y. Wu, Y. Shao, Y. Zhong, J. Lv and X. Hao, Nano Energy, 2016, 27, 466-474, doi: 10.1016/j.nanoen.2016.07.014.

[42] S. Ma, J. Xie, J. Wen, K. He, X. Li, W. Liu and X. Zhang, Appl. Surf. Sci., 2017, 391, 580-591, doi: 10.1016/J.APSUSC.2016.07.067.

[43] H. Yang, J. Li, L. Yu, B. Huang, Y. Ma and Y. Dai, J. Mater. Chem., 2018, 6, 4161-4166, doi: 10.1039/C7TA10624F.

[44] H.-y. Zhang, Optoelectronics Letters, 2016, 12, 81-84, doi: 10.1007/S11801-016-5240-1.

[45] R. Chen, B. Han, L. Yang, Y. Yang, Y. Xu and Y. Mai, J. Lumin., 2016, 172, 197-200, doi: 10.1016/J.JLUMIN.2015.12.006.

[46] B. Ren, M. Cao, Q. Zhang, J. Huang, Z. Zhao, X. Jin, C. Li, Y. Shen and L. Wang, J. Alloys Compd., 2016, 659, 74-81, doi: 10.1016/J.JALLCOM.2015.11.030.

[47] P. Elavarthi, A. A. Kumar, G. Murali, D. A. Reddy and K. Gunasekhar, J. Alloys Compd., 2016, 656, 510-517, doi: 10.1016/J.JALLCOM.2015.09.244.

[48] M. Darwish, A. Mohammadi and N. Assi, Mater. Res. Bull., 2016, 74, 387-396, doi: 10.1016/J.MATERRESBULL.2015.11.002.

[49] U. Desnica, O. Gamulin, A. Tonejc, M. Ivanda, C. White, E. Sonder and R. Zuhr, Mater. Sci. Eng. C, 2001, 15, 105-107, doi: 10.1016/S0928-4931(01)00262-4.

[50] H. Yang, C. Huang, X. Li, R. Shi and K. Zhang, Mater. Chem. Phys., 2005, 90, 155-158, doi: 10.1016/J.MATCHEMPHYS.2004.10.028.

[51] S. Chander and M. S. Dhaka, J. Mater. Sci.: Mater. Electron., 2017, 28, 6852-6859, doi: 10.1007/S10854-017-6384-X.

[52] M. Gilic, J. Trajic, N. Romcevic, M. Romcevic, D. Timotijevic, G. Stanisic and I. Yahia, Opt. Mater., 2013, 35, 11121117, doi: 10.1016/J.OPTMAT.2012.12.028.

[53] D. Meissner, C. Benndorf and R. Memming, Appl. Surf. Sci., 1987, 27, 423-436, doi: 10.1016/0169-4332(87)90152-8. 
[54] N. Kakuta, J. M. White, A. Campion, A. J. Bard, M. A. Fox and S. E. Webber, J. Phys. Chem. A, 1985, 89, 48-52, doi: 10.1021/J100247A014.

[55] Y. Gu, L. Tang, X. Guo, J. Xiang, K. S. Teng and S. P. Lau, Chin. Phys. B, 2019, 28, 47803, 1-6, doi: 10.1088/16741056/28/4/047803.

[56] S. Patra, P. Mitra and S. K. Pradhan, Mater. Res-Ibero-Am. J., 2011, 14, 17-20, doi: 10.1590/S1516-14392011005000015.

[57] N. Soltani, E. Saion, M. Z. Hussein, M. Erfani, A. Abedini, G. Bahmanrokh, M. Navasery and P. Vaziri, Int. J. Mol. Sci., 2012, 13, 12242-12258, doi: 10.3390/IJMS131012242.

\section{Author information}

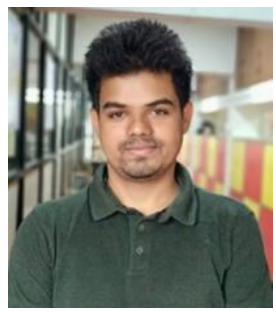

Ganesh K. Rahane is Research Scholar at Department of Physics and School of Energy Studies, Savitribai Phule Pune University, Pune 411007 (India).

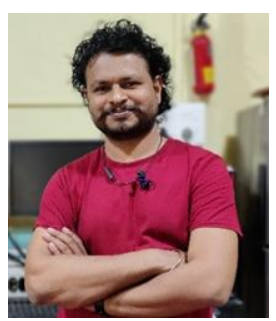

Yogesh A. Jadhav is currently working as Savitribai Phule Postdoctoral Fellow (SPPU PDF) at School of Energy Studies, Savitribai Phule Pune University, Pune. He has obtained his MS degree in Nanotechnology with $1^{\text {st }}$ Rank. He was awarded with DST INSPIRE Fellowship (2013) for Pursuing his Ph.D. in Physical Chemistry (2018) from Savitribai Phule Pune University, Pune. He has worked as Scientist C in National Centre for Nanoscience and Nanotechnology Mumbai University, Mumbai (2019). His research is focused on Semiconductor Nanocrystals/Quantum dot Synthesis, thin-film deposition, Electrochemistry for energy harvesting and storage devices like Solar cells, Batteries and Supercapacitors.

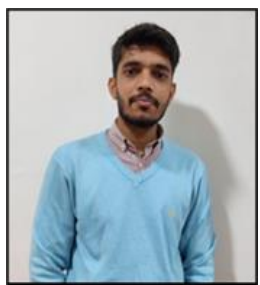

Sunil V. Barma is currently working as a Research Scholar at the School of Energy Studies, Savitribai Phule Pune University, Pune 411007 (India). His research interest area includes Structural, Optical and Photoelectrochemical investigation of binary, ternary and quaternary semiconductors and their heterostructures for Photovoltaic and water splitting application.

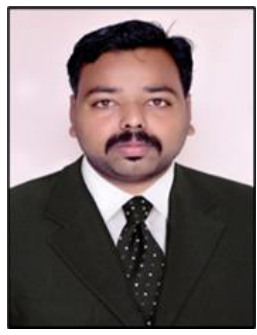

Avinash V. Rokade completed two Masters Degrees (M.Sc. in 2012 and M.Phil. in 2014) and during he has gained some expertise in nanomaterial's synthesis by the chemical route and their application for photocatalytic water splitting for hydrogen gas evolution. He was awarded NREF (National Renewable Energy Fellowship) of MNRE, Govt. of India to pursue Ph. D. at School of Energy, Savitribai Phule Pune University from 2014 to 2018. He has been awarded a Ph. D. in physics from the Department of Physics, Savitribai Phule Pune University, Pune in 2018.He has published more than 30 research articles and 2 book chapters in peer-reviewed journals. Presently, he is Assistant Professor at the School of Energy Studies, Savitribai Phule Pune University, Pune working in the field of optoelectronic devices, mainly to improve PEC the efficiency with help of $1 D$, $2 D$, and $3 D$ nanostructures and investigation of their interfacial properties via Photo Electrochemical Impedance Spectroscopy, Cyclic Voltammetry, Chrono methods, and Mott-Schottky analysis for photo-generated charge-transfer dynamics.

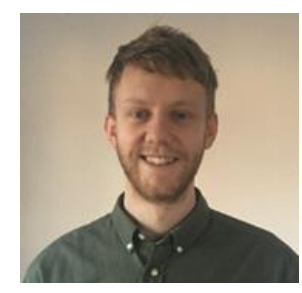

Russell W. Cross is a graduate from Cardiff University, where he gained MSc in Catalysis and a BSc in Chemistry degrees. Russell's PhD research involves computer-aided design of transition metal phosphides for efficient hydrogen evolution reaction. He is also working on the rational design of bimetallic Ni-based catalyst for direct hydrazine fuel cell (DHFC) technology.

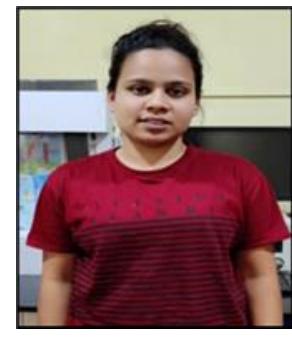

Mamta P. Nasane is currently working as a Research Scholar at School of Energy Studies, Savitribai Phule Pune University, and Pune, India. Her research interest is An Interlinked ComputationalExperimental Investigation into SnS Nano-Flakes for Field Emission Application.

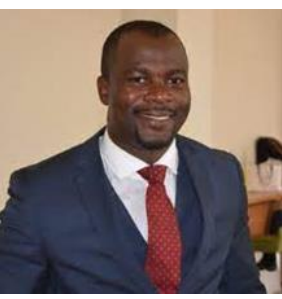

Nelson Dzade is an EPSRC Innovation Research Fellow and leads the Materials Research Driven by Computation Group in the School of Chemistry at Cardiff University. Nelson received his Ph.D. from the University College London (UCL) in 2014, where he worked on "Unraveling the interactions of organic molecules with the surfaces of iron-bearing minerals". He then worked as a postdoctoral researcher at Utrecht University, The Netherlands on the "Computer-aided design of iron-sulfide nanocatalysts for the solar-driven conversion of CO2 to fuels". He was awarded the prestigious EPSRC Innovation Fellowship in 2018, and he has since become an Independent Research Group Leader in the School of Chemistry, Cardiff University. He was also awarded the DUO-India Professor Fellowship Award in 2020, enabling him to establish highprofile collaborations with leading Indian Scientists.

Publisher's Note: Engineered Science Publisher remains neutral with regard to jurisdictional claims in published maps and institutional affiliations. 